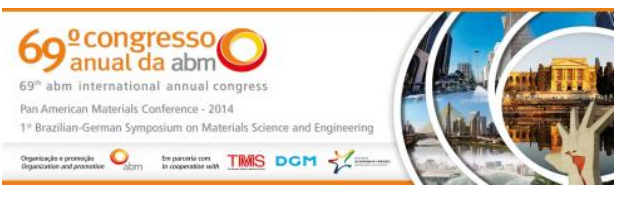

Tema: Lavra e Tratamento de Minérios

\title{
PURIFICAÇÃO DE NÍQUEL CONTIDO EM LICORES SINTÉTICOS DE LIXIVIAÇÃO UTILIZANDO-SE EXTRAÇÃO POR SOLVENTES COM MISTURAS DE EXTRATANTES*
}

\section{Resumo}

\author{
Alexandre Silva Guimarães ${ }^{1}$ \\ Priscila Siqueira da Silva ${ }^{2}$ \\ Marcelo Borges Mansur ${ }^{3}$
}

Este trabalho avaliou a purificação de níquel em relação aos contaminantes cálcio e magnésio a partir de soluções sintéticas sulfúricas simulando os licores industriais obtidos pelo processo de lixiviação sob pressão de minérios lateríticos de níquel. $O$ uso de Cyanex $272(20 \%$ v/v) se mostrou ineficiente na purificação do licor em decorrência das extrações simultâneas de magnésio e níquel e pela baixa seletividade do Cyanex 272 em relação ao cálcio (extrações inferiores a 10\%). A adição de 5\% v/v de ácido naftênico ao Cyanex 272 (20\% v/v) provocou a extração conjunta de magnésio e níquel e extrações insignificantes de cálcio (inferiores a 0,5\%). A mistura de $20 \%$ v/v de Cyanex $272 \mathrm{com} 20 \%$ v/v de D2EHPA, em pH = 4,5, é passível de promover a purificação do licor frente ao níquel, pelo fato desta combinação de reagentes extrair cerca de $50 \%$ de cálcio, $48 \%$ de magnésio com baixos teores de níquel (em torno de 10\%), podendo-se utilizar dois estágios de contactação para se obter no mínimo $80 \%$ de níquel purificado em fase aquosa.

Palavras-chave: Níquel; Cyanex 272; D2EHPA; Ácido naftênico.

\section{PURIFICATION OF NICKEL CONTAINED IN SYNTHETIC LEACH LIQUORS USING SOLVENT EXTRACTION WITH MIXTURES OF EXTRACTANTS}

\begin{abstract}
This study evaluated the purification of nickel with respect to contaminants calcium and magnesium from sulfuric synthetic solutions simulating industrial liquors obtained from the pressure leaching of nickel lateritic ores. The use of Cyanex $272(20 \% \mathrm{v} / \mathrm{v})$ was inefficient in the purification of liquor due to the simultaneous extraction of magnesium and nickel and low selectivity of Cyanex 272 in relation to calcium (less than $10 \%$ of extraction). The addition of $5 \% \mathrm{v} / \mathrm{v}$ naphthenic acid to Cyanex 272 (20\% $\mathrm{v} / \mathrm{v}$ ) caused the extraction simultaneously magnesium and nickel, while the extraction of calcium was insignificant (less than $0.5 \%$ ). The mixture of $20 \% \mathrm{v} / \mathrm{v}$ Cyanex 272 with $20 \% \mathrm{v} / \mathrm{v}$ D2EHPA, at $\mathrm{pH}=4.5$, is likely to promote the purification of the liquor in relation to nickel because this combination of reagents extract about $50 \%$ of calcium, $48 \%$ of magnesium simultaneously with low nickel content (about $10 \%$ ), it could be used two stages to obtain at least $80 \%$ of nickel purified in the aqueous phase.
\end{abstract}

Keywords: Nickel; Cyanex 272; D2EHPA; Naphtenic acid.

1 Engenheiro Metalurgista, Mestre, Doutorando em Engenharia Metalúrgica, Materiais e de Minas, PPGEM, UFMG, Belo Horizonte, MG, Brasil.

2 Graduanda em Engenharia Metalúrgica, UFMG, Belo Horizonte, MG, Brasil.

3 Engenheiro Químico, Doutor, Prof. Associado, Dep. Eng. Metalúrgica e de Materiais, UFMG, Belo Horizonte, MG, Brasil.

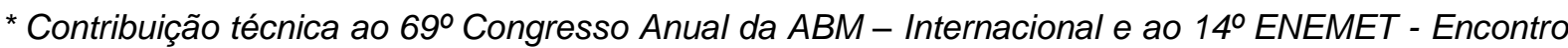
Nacional de Estudantes de Engenharia Metalúrgica, de Materiais e de Minas, 21 a 25 de julho de 2014, São Paulo, SP, Brasil.
} 


\section{INTRODUÇÃO}

O níquel constitui uma das espécies metálicas de maior relevância comercial atualmente. A recuperação da crise econômica mundial a partir de 2010 e a crescente demanda da China por níquel para a fabricação de aço inoxidável possibilitaram incrementos nos valores deste metal e conduziram novos investimentos para a produção de níquel concentrado e purificado no Brasil [1]. De acordo com o Instituto de metais não ferrosos - ICZ [2], o território brasileiro possui mais de 8 milhões de toneladas de minérios lateríticos de níquel. Logo, a produção de níquel a partir das lateritas torna-se cada vez mais importante estrategicamente, uma vez que os depósitos de minérios sulfetados de níquel encontram-se cada vez mais escassos, conforme relatado por Oliveira [3].

Os minérios lateríticos de níquel, após as operações de beneficiamento, tais como: britagem, moagem, concentração e separação solido-liquido; podem ser submetidos a um tratamento hidrometalúrgico. Nesta etapa, ocorre, em autoclaves, a lixiviação das lateritas de níquel utilizando-se ácido sulfúrico como agente lixiviante, sob condições de elevadas temperaturas (entre 250 e $270^{\circ} \mathrm{C}$ ) e pressões (entre 1 e 2 atm). Este processo é denominado de HPAL (High Pressure Acid Leaching). A polpa proveniente deste estágio é filtrada para separar o licor dos minerais de ganga. Os licores de lixiviação industrial apresentam elevadas concentrações de níquel (entre 70 e 100g/L) associado a outros metais como cálcio, cobalto, cobre, ferro, manganês, magnésio e zinco em concentrações comparativamente mais baixas (entre 0,07 e 3,04 g/L). O ferro é precipitado, aquecendo-se o licor em uma temperatura entre 150 e $200^{\circ} \mathrm{C}$ [4], na forma de jarosita ou hematita, sendo, desta maneira, separado dos outros metais. Para purificar e concentrar o níquel em relação aos outros contaminantes utiliza-se a técnica de extração por solventes [5]. A extração por solventes é utilizada para remover, separar e concentrar espécies metálicas dissolvidas em meio aquoso [6]. O licor ou fase aquosa é colocado em contato com outro liquido imiscível, denominado de fase orgânica, a qual se caracteriza por conter um ou mais extratantes solubilizados em um diluente orgânico [7]. A separação dos metais cobalto, cobre, manganês e zinco do licor frente ao níquel é realizada com eficiência utilizando-se o extratante Cyanex 272 (ácido 2,4,4trimetil-pentil fosfínico). No entanto, conforme demonstrado por Flett [8] e Guimaraes [9], a purificação do níquel em relação aos metais alcalinos terrosos, cálcio e magnésio, é desfavorecida pelo uso do Cyanex 272.

Diante deste cenário, a separação do níquel dos contaminantes, cálcio e magnésio, pode ser favorecida misturando-se dois ou mais extratantes comercialmente disponíveis na fase orgânica [10]. Estes sistemas orgânicos são chamados de sistemas extrativos sinérgicos. Segundo Rydberg [4], o ácido naftênico (um tipo de ácido carboxílico) extrai níquel numa faixa de $\mathrm{pH}$ entre 4,0 e 6,5. Desta maneira, o uso deste reagente juntamente com o Cyanex 272 pode favorecer a extração de níquel em relação aos metais cálcio e magnésio. De acordo com a série preferencial de extração de Flett [8], o extratante D2EHPA (ácido di-2-etilhexil fosfórico) tem maior afinidade para extrair cálcio e magnésio em detrimento ao níquel. Logo este extratante misturado com o Cyanex 272 pode acarretar na purificação do licor frente ao níquel. Neste contexto, este trabalho propõe avaliar o uso de misturas entre os extratantes Cyanex 272 e ácido naftênico e entre Cyanex 272 e D2EHPA visando à purificação de níquel no licor em relação aos contaminantes cálcio e magnésio.

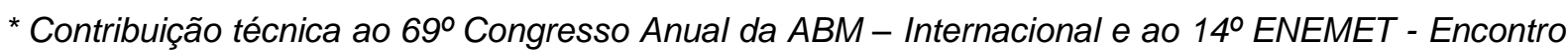
Nacional de Estudantes de Engenharia Metalúrgica, de Materiais e de Minas, 21 a 25 de julho de 2014, São Paulo, SP, Brasil.
} 


\section{MATERIAIS E MÉTODOS}

\subsection{Licor Sintético de Lixiviação}

Um licor sintético de lixiviação foi preparado com os metais de interesse: níquel (88 g/L), cálcio $(0,50 \mathrm{~g} / \mathrm{L})$ e magnésio $(3,04 \mathrm{~g} / \mathrm{L})$, em níveis de concentrações semelhantes aos licores industriais obtidos pelo processo HPAL. Os reagentes utilizados de grau analítico $\left(\mathrm{NiSO}_{4} .6 \mathrm{H}_{2} \mathrm{O}, \mathrm{CaSO}_{4} .2 \mathrm{H}_{2} \mathrm{O}, \mathrm{MgSO}_{4} .7 \mathrm{H}_{2} \mathrm{O}, \mathrm{H}_{2} \mathrm{SO}_{4}\right.$, marca Synth) foram dissolvidos em um becker com água destilada. Em seguida, o licor foi filtrado (para remover eventuais sólidos em suspensão) e homogeneizado em um balão volumétrico.

\subsection{Soluções Orgânicas}

Os extratantes Cyanex 272, D2EHPA e ácido naftênico são compostos orgânicos catiônicos. O Cyanex 272 e o D2EHPA são derivados de ésteres ortofosfóricos, ácidos fosfóricos e ácidos fosfínicos [4]. A amostra de Cyanex 272 (peso molecular: $290 \mathrm{~g} / \mathrm{mol}$; densidade $\left.\left(24^{\circ} \mathrm{C}\right): 0,92 \mathrm{~g} / \mathrm{cm}^{3}\right)$ usada nos experimentos desta pesquisa foi fornecida pela Cytec Canadá. O D2EHPA possui peso molecular igual a $322,4 \mathrm{~g} / \mathrm{mol}$ e densidade $\left(24^{\circ} \mathrm{C}\right)$ igual a $0,97 \mathrm{~g} / \mathrm{cm}^{3}$. Os ácidos naftênicos (densidade $\left(20^{\circ} \mathrm{C}\right): 0,92 \mathrm{~g} / \mathrm{cm}^{3}$, marca Sigma-Aldrich), de uma maneira geral, representam um grupo diverso de ácidos carboxílicos saturados, sendo predominantemente monocarboxílicos e são diferenciados pela cadeia hidrocarbônica [11]. O n-heptano $\left(\mathrm{C}_{7} \mathrm{H}_{16}\right)$ (grau analítico e marca Synth) foi utilizado como diluente no preparo das soluções orgânicas. Na Tabela 1, são apresentadas as concentrações dos extratantes e as condições de acidez da fase aquosa avaliadas nos três ensaios de extração por solventes realizados neste estudo.

Tabela 1. Composição da fase orgânica e variação de acidez dos ensaios de extração por solventes

\begin{tabular}{ccccc}
\hline Ensaio & $\begin{array}{c}\text { Cyanex 272 } \\
(\% \mathrm{v} / \mathrm{v})\end{array}$ & D2EHPA $(\% \mathrm{v} / \mathrm{v})$ & $\begin{array}{c}\text { ácido naftênico } \\
(\% \mathrm{v} / \mathrm{v})\end{array}$ & $\begin{array}{c}\text { faixa de } \mathrm{pH} \\
\text { analisada }\end{array}$ \\
\hline 1 & 20 & - & - & $\begin{array}{c}\text { entre } 2,0 \mathrm{e} \\
7,0\end{array}$ \\
\hline 2 & 20 & - & 5 & $\begin{array}{c}\text { entre } 4,0 \mathrm{e} \\
7,0\end{array}$ \\
\hline 3 & 20 & 20 & - & $\begin{array}{c}\text { entre } 3,5 \mathrm{e} \\
7,5\end{array}$ \\
\hline
\end{tabular}

\subsection{Ensaios de Extração por Solventes}

Os três ensaios de extração por solventes foram realizados colocando-se em contato em um reator de vidro de $1 \mathrm{~L}, 200 \mathrm{~mL}$ do licor sintético sulfúrico, em seguida, foram adicionados $200 \mathrm{~mL}$ de solução orgânica mantendo-se a razão entre os volumes das fases aquosa $(A)$ e orgânica $(O) A / O$ igual a 1 . O reator de vidro foi acoplado a um banho-maria digital (marca Kacil, modelo RM-02) com a finalidade de as soluções atingirem uma temperatura igual a $50^{\circ} \mathrm{C}$, semelhante à utilizada em processos industriais de extração por solventes. Alcançando-se este valor de temperatura, as fases aquosa e orgânica foram agitadas com o auxilio de um agitador mecânico (velocidade de $400 \mathrm{rpm}$, marca lka, modelo RW 20N) durante 5 minutos. Após este tempo, as soluções foram mantidas em repouso por 3 minutos,

\footnotetext{
* Contribuição técnica ao $69^{\circ}$ Congresso Anual da ABM - Internacional e ao 14ํㅡㄹ ENEMET - Encontro Nacional de Estudantes de Engenharia Metalúrgica, de Materiais e de Minas, 21 a 25 de julho de 2014, São Paulo, SP, Brasil.
} 


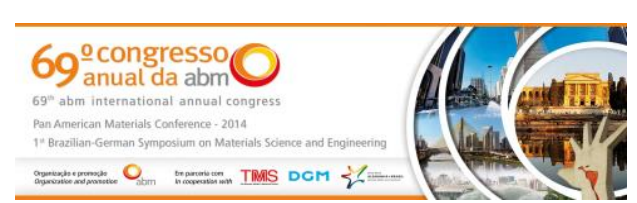

permitindo-se alcançar o equilíbrio liquido-liquido entre as fases [12]. Na Figura 1, é apresentada a montagem experimental utilizada nos ensaios de extração por solventes.

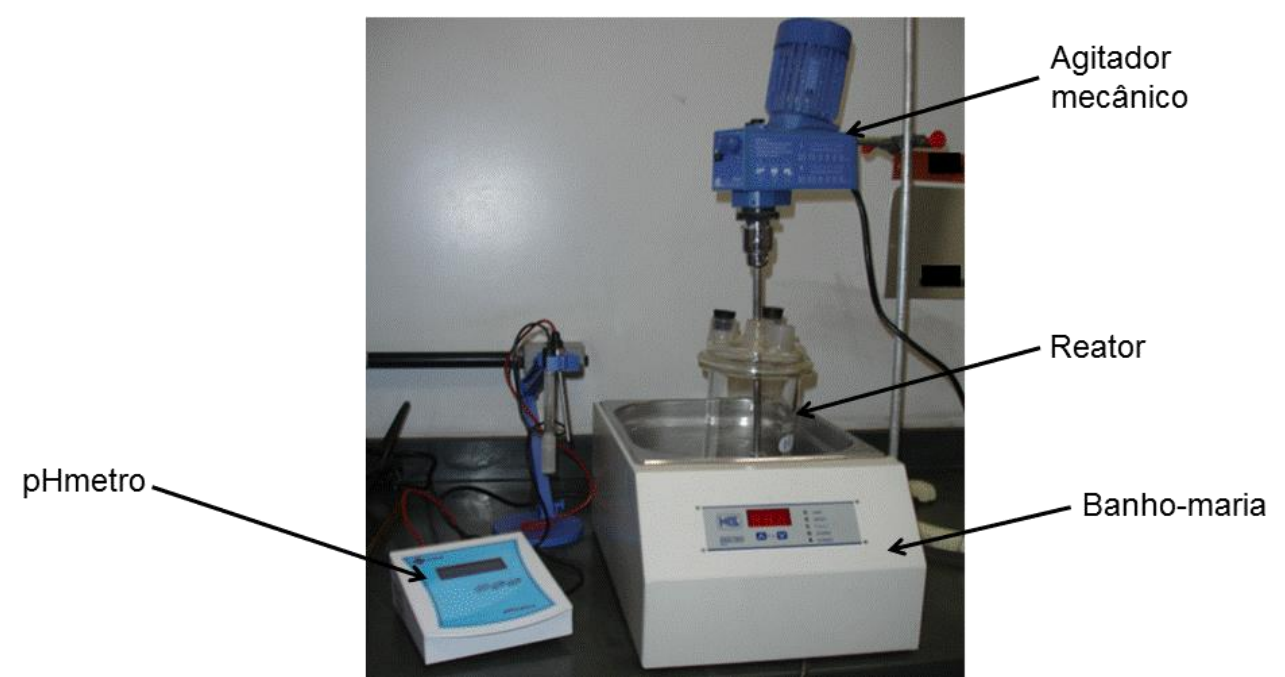

Figura 1. Representação da montagem experimental utilizada nos ensaios de extração por solventes.

$\mathrm{O}$ pH foi medido com o auxílio de um pHmetro (marca Quimis, modelo $0400 \mathrm{AS}$ ) e foram retiradas alíquotas de $10 \mathrm{~mL}$ do licor sintético de lixiviação em cada valor de pH especificado (aproximadamente 2,0; 3,0; 4,0; 4,5; 5,0; 5,5; 6,0; 6,5; e 7,0). Foi observada durante a realização dos experimentos, uma pequena evaporação de nheptano. No entanto, a razão $\mathrm{A} / \mathrm{O}$ foi mantida unitária em função do recolhimento de alíquotas apenas da fase aquosa. $\mathrm{O}$ pH foi ajustado gotejando-se solução de 5 e 10 $\mathrm{mol} / \mathrm{L}$ de hidróxido de sódio ( $\mathrm{NaOH}$; marca Synth, grau analítico) durante a agitação das soluções aquosa e orgânica.

\subsection{Procedimento Analítico}

As concentrações dos metais referente às alíquotas retiradas do licor durante os ensaios de extração por solventes foram analisadas por espectrofotometria de absorção atômica, EAA, (espectrofotômetro marca Perkin Elmer AAnalyst, modelo 300) pelo laboratório de análises químicas (LAQ) do departamento de Engenharia Metalúrgica, Materiais e de Minas da UFMG. A transferência de massa dos metais para a fase orgânica foi calculada por balanço de massa mediante os valores das concentrações dos metais obtidos por EAA.

\section{RESULTADOS E DISCUSSÃO}

Na Figura 2, são apresentados os resultados dos ensaios de extração por solventes dos metais cálcio, magnésio e níquel utilizando-se os extratantes Cyanex 272 (20\% $\mathrm{v} / \mathrm{v})$ e ácido naftênico $(0$ e $5 \% \mathrm{v} / \mathrm{v})$ variando-se a condição de acidez do licor $(2<\mathrm{pH}<7)$.

\footnotetext{
* Contribuição técnica ao 69ำ Congresso Anual da ABM - Internacional e ao 14ํㅡㄹ ENEMET - Encontro Nacional de Estudantes de Engenharia Metalúrgica, de Materiais e de Minas, 21 a 25 de julho de 2014, São Paulo, SP, Brasil.
} 

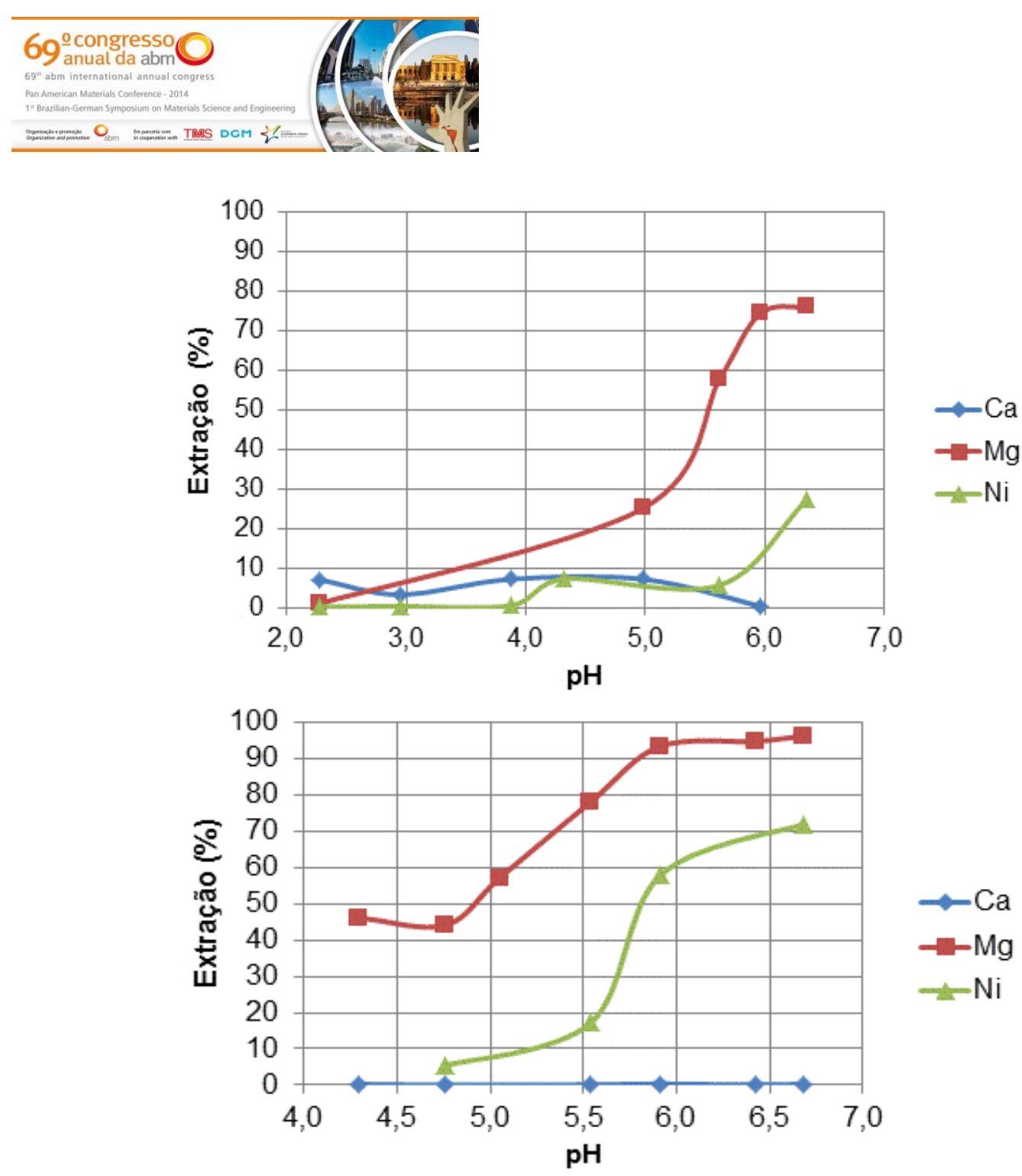

(a)

(b)

Figura 2. Extração dos metais cálcio, magnésio e níquel contidos no licor sintético de lixiviação utilizando-se (a) $20 \%$ v/v de Cyanex 272 e (b) $20 \%$ v/v de Cyanex $272 \mathrm{com} 5 \%$ v/v de ácido naftênico, diluídos em n-heptano (temperatura igual a $50^{\circ} \mathrm{C}$ e $\mathrm{A} / \mathrm{O}=1$ ).

O uso de Cyanex 272 como extratante (Figura 2(a)) promoveu extrações de elevados teores de magnésio (de 13 a 76\%), numa faixa de $\mathrm{pH}$ entre 4,0 e 6,5, porém, conjuntamente com o níquel (de 1 a $25 \%$ ), dificultando a purificação do licor em relação a esta ultima espécie metálica. Pode ser observado que as extrações de cálcio são inferiores a 10\% em toda a faixa de pH analisada, entre 2,0 e 7,0. Desta forma, permanecem em fase aquosa aproximadamente $90 \%$ de cálcio juntamente com cerca de $75 \%$ de níquel no licor, refletindo a dificuldade de separação dos metais alcalinos terrosos, cálcio e magnésio, em relação ao níquel, utilizando-se Cyanex 272 como único extratante corroborando os estudos realizados por Devi [13] e Flett [8].

A adição de $5 \% \mathrm{v} / \mathrm{v}$ de ácido naftênico na fase orgânica contendo $20 \% \mathrm{v} / \mathrm{v}$ de Cyanex 272 (Figura 2(b)) acarretou na extração de magnésio (cerca de 96\%) conjuntamente com o níquel (em torno de $70 \%$ ) em pH igual a 6,95, enquanto o cálcio praticamente não foi extraído do licor (extrações inferiores a $0,5 \%$ ) em toda a faixa de $\mathrm{pH}$ estudada, entre 4,0 e 7,0. A seletividade dos contaminantes cálcio e magnésio em relação ao níquel foi calculada pelo fator de separação de acordo com a equação (1):

$\beta_{\text {Metal } / N i}=\frac{D_{M e t a l}}{D_{N i}}$

\footnotetext{
* Contribuição técnica ao 69 Congresso Anual da ABM - Internacional e ao 14ํㅡㄹ ENEMET - Encontro Nacional de Estudantes de Engenharia Metalúrgica, de Materiais e de Minas, 21 a 25 de julho de 2014, São Paulo, SP, Brasil.
} 


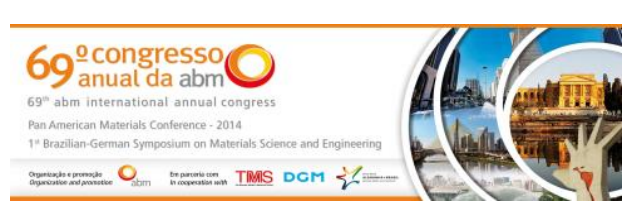

em que DMetal é o coeficiente de distribuição do metal (neste contexto: cálcio ou magnésio) obtido pela razão entre a concentração do metal na fase orgânica pela concentração do metal na fase aquosa em equilíbrio com a fase orgânica. Similarmente, o $D_{\mathrm{Ni}}$ representa o coeficiente de distribuição do níquel (obtido pela razão da concentração de níquel na fase orgânica pela concentração desta espécie metálica no licor, em equilíbrio com a solução orgânica).

A baixa seletividade dos extratantes Cyanex $272(20 \% \mathrm{v} / \mathrm{v})$ e ácido naftênico (5\% $\mathrm{v} / \mathrm{v}$ ), ou seja, os baixos valores dos $\beta \mathrm{ca} / \mathrm{Ni}$, mostrados na Tabela 2 , ocorre em função da extração de níquel em detrimento do cálcio, indicando uma maior dificuldade de

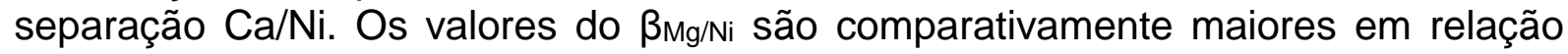
aos valores de $\beta \mathrm{Ca} / \mathrm{Ni}$ revelando que a separação do magnésio em relação ao níquel é mais fácil do que a separação $\mathrm{Ca} / \mathrm{Ni}$. Desta maneira, a combinação de $5 \% \mathrm{v} / \mathrm{v}$ de ácido naftênico e $20 \% \mathrm{v} / \mathrm{v}$ de Cyanex 272 possibilita a separação dos metais magnésio e níquel do licor, em $\mathrm{pH}$ igual a 6,95, em relação ao cálcio, que permanece em solução aquosa, permitindo o estudo da purificação do níquel em relação ao magnésio utilizando-se outros extratantes e/ou misturas de extratantes.

Tabela 2. Fatores de separação, $\beta_{\mathrm{Ca} / \mathrm{Ni}}$ e $\beta_{\mathrm{Mg} / \mathrm{Ni}}$, em função do $\mathrm{pH}$, utilizando-se $20 \%$ v/v de $\mathrm{Cyanex}$ 272 com 5\% v/v de ácido naftênico

\begin{tabular}{ccc}
\hline $\mathrm{pH}$ de equilíbrio & $\beta_{\mathrm{Ca} / \mathrm{Ni}}$ & $\beta_{\mathrm{Mg} / \mathrm{Ni}}$ \\
\hline 4,30 & 1,3 & 1,4 \\
\hline 4,76 & 0,5 & 14 \\
\hline 5,91 & 1,3 & 17 \\
\hline 6,42 & 1,1 & 10 \\
\hline 6,88 & 0,2 & 16 \\
\hline 6,95 & 0,3 & 10 \\
\hline
\end{tabular}

Na Figura 3, são mostradas as curvas de extração dos metais cálcio, magnésio e níquel, variando-se o pH do licor entre 3,5 e 7,5, utilizando-se os extratantes Cyanex $272(20 \% \mathrm{v} / \mathrm{v})$ e D2EHPA (20\% v/v).

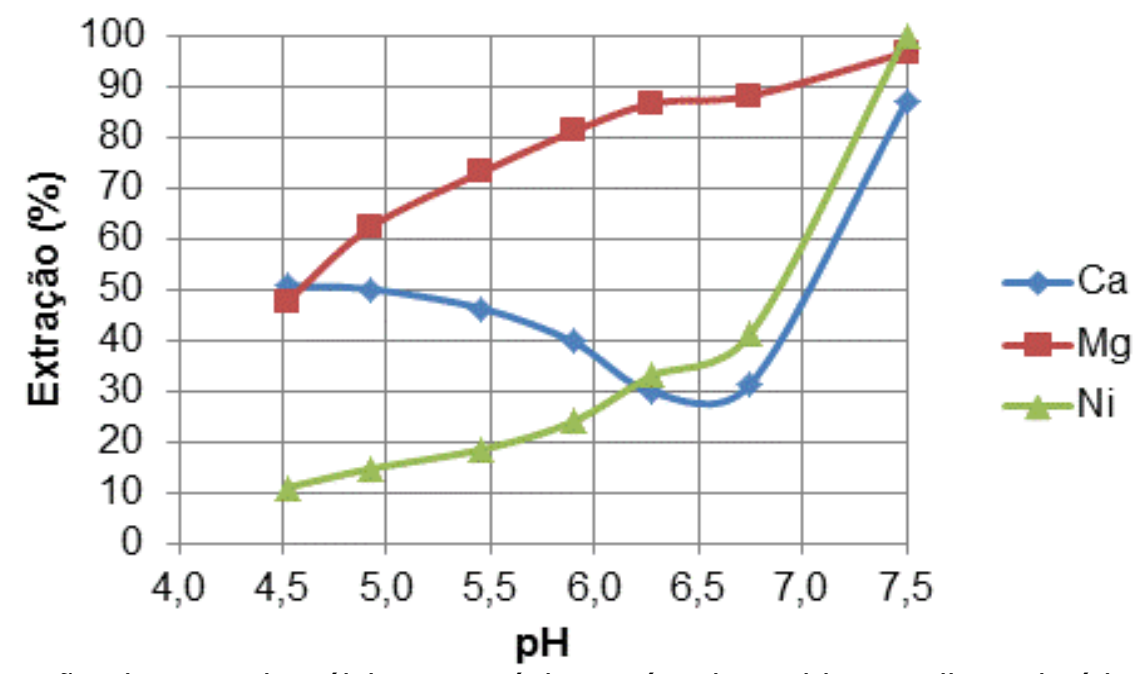

Figura 3. Extração dos metais cálcio, magnésio e níquel contidos no licor sintético de lixiviação utilizando-se $20 \% \mathrm{v} / \mathrm{v}$ de Cyanex $272 \mathrm{com} 20 \% \mathrm{v} / \mathrm{v}$ de D2EHPA, diluídos em n-heptano (temperatura igual a $50^{\circ} \mathrm{C}$ e $\mathrm{A} / \mathrm{O}=1$ ).

A mistura de 20\% v/v de D2EHPA com 20\% v/v de Cyanex 272 extrai, de uma maneira geral, preferencialmente, os metais cálcio e magnésio em detrimento ao

\footnotetext{
* Contribuição técnica ao $69^{\circ}$ Congresso Anual da ABM - Internacional e ao 14ํㅡㄹ ENEMET - Encontro Nacional de Estudantes de Engenharia Metalúrgica, de Materiais e de Minas, 21 a 25 de julho de 2014, São Paulo, SP, Brasil.
} 


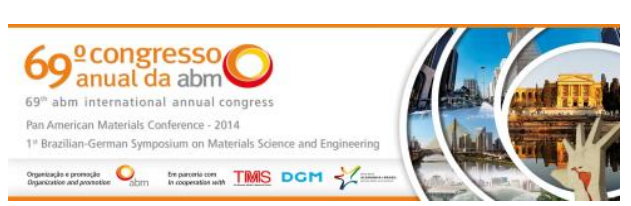

níquel, numa faixa de $\mathrm{pH}$ entre 4,5 e 6,0. Desta maneira, em $\mathrm{pH}$ igual a 4,5, que corresponde aos maiores valores simultâneos dos fatores de separação $\beta \mathrm{Ca} / \mathrm{Ni}=8,4$ e $\beta_{\mathrm{Mg} / \mathrm{Ni}}=7,4$, mostrados na Tabela 3, ocorre a possibilidade de purificação do licor em relação ao níquel, uma vez que são extraídos cerca de $50 \%$ de cálcio, $48 \%$ de magnésio com baixos teores de níquel (cerca de 10\%) podendo-se utilizar dois estágios de contactação para extração destes metais alcalinos terrosos, de maneira que permaneceriam em fase aquosa pelo menos $80 \%$ de níquel purificados, os quais podem ser enviados diretamente a uma etapa de eletrorrecuperação.

Tabela 3. Fatores de separação, $\beta_{\mathrm{Ca} / \mathrm{Ni}}$ e $\beta_{\mathrm{Mg} / \mathrm{Ni}}$, em função do $\mathrm{pH}$, utilizando-se $20 \% \mathrm{v} / \mathrm{v}$ de Cyanex $272 \mathrm{com} 20 \% \mathrm{v} / \mathrm{v}$ de D2EHPA

\begin{tabular}{ccc}
\hline $\mathrm{pH}$ de equilíbrio & $\beta_{\mathrm{Ca} / \mathrm{Ni}}$ & $\beta_{\mathrm{Mg} / \mathrm{Ni}}$ \\
\hline 4,50 & 8,4 & 7,4 \\
\hline 4,92 & 5,9 & 9,6 \\
\hline 5,46 & 3,8 & 12 \\
\hline 5,90 & 2,1 & 14 \\
\hline 6,28 & 0,9 & 13 \\
\hline 6,75 & 0,7 & 11 \\
\hline 7,50 & 0,01 & 0,04 \\
\hline
\end{tabular}

A seletividade dos extratantes Cyanex 272 (20\% v/v) e D2EHPA (20\% v/v) para valores de $\mathrm{pH}>6$, tende a diminuir em decorrência dos valores dos fatores de

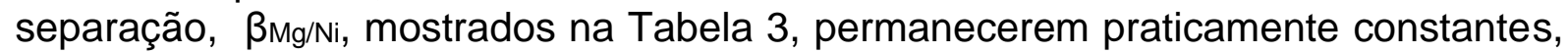
evidenciando a dificuldade de separação do níquel em relação ao magnésio, e pelo fato de maiores teores de níquel serem extraídos conjuntamente com o cálcio, menores valores, $\beta \mathrm{Ca} / \mathrm{Ni}$, revelando, de uma maneira geral, a dificuldade de purificação do cálcio frente ao níquel em condições de menor acidez do licor.

\section{CONCLUSÃO}

Este trabalho avaliou a purificação de licores sintéticos de lixiviação contendo os metais cálcio, magnésio e níquel em concentrações similares aos licores industriais obtidos pelo processo HPAL utilizando-se os extratantes Cyanex 272, ácido naftênico e D2EHPA. As principais conclusões obtidas são apresentadas a seguir:

- O uso de Cyanex 272 (20\% v/v) dificulta a purificação do licor sintético de lixiviação em decorrência da extração simultânea de elevados teores de magnésio (de 13 a 76\%) com o níquel (de 1 a $25 \%$ ), numa faixa de $\mathrm{pH}$ entre 4,0 e 6,5; O Cyanex 272 não é seletivo para o cálcio (extrações inferiores a $10 \%$ ) de maneira que aproximadamente $90 \%$ desta espécie metálica permaneceram no licor juntamente com cerca de $75 \%$ de níquel;

- A adição de 5\% v/v de ácido naftênico ao Cyanex $272(20 \%$ v/v) acarretou na não extração de cálcio do licor (extrações inferiores a $0,5 \%$ ), permitindo a extração de magnésio (cerca de 96\%) e de níquel (em torno de 70\%) do licor em $\mathrm{pH}$ igual a 6,95, possibilitando-se o estudo da purificação do licor contendo magnésio e níquel com outros extratantes e/ou misturas de extratantes;

- A mistura de $20 \%$ v/v de D2EHPA com 20\% v/v de Cyanex 272 permite a purificação do licor em relação ao níquel, em $\mathrm{pH}=4,5$ (maiores valores simultâneos das seletividades $\beta_{\mathrm{Ca} / \mathrm{Ni}}=8,4$ e $\left.\beta_{\mathrm{Mg} / \mathrm{Ni}}=7,4\right)$, pelo fato desta combinação de reagentes extrair aproximadamente $50 \%$ de cálcio, $48 \%$ de

\footnotetext{
* Contribuição técnica ao $69^{\circ}$ Congresso Anual da ABM - Internacional e ao 14ํㅡㄹ ENEMET - Encontro Nacional de Estudantes de Engenharia Metalúrgica, de Materiais e de Minas, 21 a 25 de julho de 2014, São Paulo, SP, Brasil.
} 


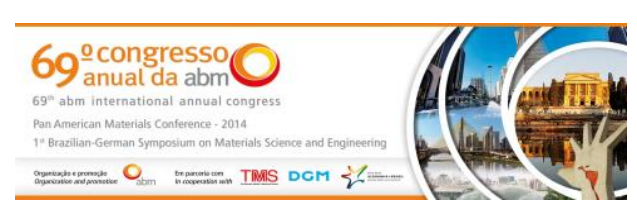

magnésio conjuntamente com baixos teores de níquel (cerca de 10\%), podendo-se utilizar dois estágios de contactação para extração de cálcio e magnésio, de maneira que permaneceriam em fase aquosa no mínimo $80 \%$ de níquel purificados. Esta solução pode ser encaminhada diretamente a uma etapa de eletrorrecuperação de níquel.

\section{Agradecimentos}

Os autores deste trabalho agradecem à Cytec pelo fornecimento de Cyanex 272, ao Laboratório de Análises Químicas do DEMET/UFMG pelas análises realizadas, ao apoio financeiro do CNPq (CT-Mineral, Processo 550243/2011-9). Também agradecem a bolsa de doutorado do CNPq, à FUMP/UFMG, à FAPEMIG, à CAPES e ao INCT-Acqua (Instituto Nacional de Ciência e Tecnologia em Recursos Minerais, Água e Biodiversidade www.acqua-inct.org).

\section{REFERÊNCIAS}

1 Instituto brasileiro de mineração. Brasília: IBRAM, 2011[acesso em 5 de março de 2014]. Disponível em: www.ibram.org.br/sites /1300/382/0001669.pdf.

2 Instituto de metais não ferrosos. São Paulo: ICZ, 2014 [acesso em 9 de março de 2014]. Disponível em: http://www.icz.org.br/niquel.php.

3 Oliveira SMB. Estágio atual acerca do minério laterítico de níquel no Brasil e no mundo. Revista IG. 1990;11:49-57.

4 Rydberg J, Cox M, Musikas C, Choppin GR. Principles and practices of solvent extraction. 2ed. New York: Marcel Dekker; 2004.

5 Sun X, Ji Y, Zhang L, Chen J, Li D. Separation of cobalt and nickel using inner synergistic extraction from bifunctional ionic liquid extractant (Bif-ILE). Journal of Hazardous Materials. 2010;182:447-452.

6 Ndlovu B, Mahlangu, T. Calcium and magnesium rejection from sulphate solutions in lateritic nickel solvent extraction using Versatic 10 acid-Lix ${ }^{\circledR} 84$ IC system. Template Journal. 2008;108:223-227.

7 Ritcey GM, Ashbrook AW. Solvent extraction - Principles and applications to process metallurgy. New York: Elsevier, 1984.

8 Flett DS. Solvent extraction in hydrometallurgy: the role of organophosphorus extractants. Journal of Organometallic Chemistry, 2005;609:2426-2438.

9 Guimaraes AS. Purificação de níquel a partir de soluções sulfúricas por extração por solventes utilizando-se Cyanex 272 e misturas de extratantes [dissertação de mestrado]. Belo Horizonte: Universidade Federal de Minas Gerais; 2014.

10 Cheng CY, Boddy G, Zhang W, Godfrey M, Robinson DJ, Pranolo Y, et al. Recovery of nickel and cobalt from laterite leach solutions using direct solvent extraction: Part 1 selection of a synergistic SX system. Hydrometallurgy. 2010;104:45-52.

11 Campos M. Estudo dos ácidos naftênicos do gasóleo pesado derivado do petróleo marlim [tese de doutorado]. Porto Alegre: Universidade Federal do Rio Grande do Sul; 2012.

12 Mansur MB, Morais BS. Characterization of the reactive test system $\mathrm{ZnSO}_{4} / \mathrm{D} 2 \mathrm{EHPA}$ in n-heptane. Hydrometallurgy. 2004;74:11-18.

13 Devi N, Nathsarma K, Chakravortt V. Separation and recovery of cobalt (II) and nickel (II) from sulphate solutions using sodium salts of D2EHPA, PC 88A and Cyanex 272. Hydrometallurgy. 1998;49:47-61.

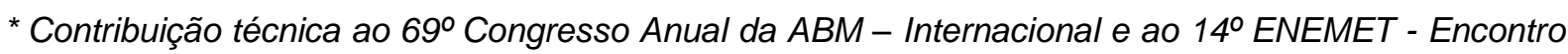
Nacional de Estudantes de Engenharia Metalúrgica, de Materiais e de Minas, 21 a 25 de julho de 2014, São Paulo, SP, Brasil.
} 